CESIS Electronic Working Paper Series

Paper No. 421

\title{
The Geography of Innovation and Entrepreneurship
}

\author{
Mikaela Backman \\ Hans Lööf
}

September, 2015 


\title{
The Geography of Innovation and Entrepreneurship
}

\author{
Mikaela Backman ${ }^{1}$ and Hans Lööf ${ }^{2}$
}

\begin{abstract}
This introduction to the special issue "The Geography of Innovation and Entrepreneurship" in Annals of Regional Science surveys a collection of nine papers which consider agglomeration economies and spatial heterogeneity of regions and firms through the lenses of innovation and entrepreneurship. They all make use of extensive and detailed data sources that enable models to provide a richer picture of how firms, industries and regions are affected by innovation and entrepreneurship but also how these entities shape and foster renewal. These factors include spatial concentration, industry composition, labour market characteristics, immigration, firm characteristics, R\&D activities and R\&D collaboration. The papers add to the understanding of the geography of innovation and entrepreneurship by suggesting alternative ways of identifying spillovers, combing and integrating internal and external knowledge sources, and by estimating the impact on innovation, new firm formation and growth.
\end{abstract}

Keywords: Innovation, entrepreneurship, spillovers, agglomeration, spatial heterogeneity

JEL Classification: C1, 03, R1

\footnotetext{
1 Jönköping University

2 Royal Institute of Technology, Stockholm
} 


\section{Introduction}

While theories of location advantages have been available since Marshall (1890) in the nineteenth century, more recently, researchers have begun to take an interest in the relationship between geography, knowledge and innovation. An important explanation is the ongoing transition from resource dependence to an innovation-driven knowledgebased economy, and the related globalization of goods and services production. This has increased the interest in factors that may affect a region's attractiveness and growth potential. An important contributory factor is the emergence of endogenous growth theory and its prominent role for R\&D, externalities and mechanisms of spillovers. Resent research on the economic importance of places has also been facilitated by improved data availability on individuals, firms and their precise spatial coordinates.

Over the last two decades, empirical studies within the area of economic geography have produced abundance of evidence that some places are more favorable than others for economic activities. ${ }^{3}$ The literature provides overwhelming amount of evidence that economically valuable knowledge is more concentrated than production and employment. ${ }^{4}$ Recent research also shows that dense urban environments with a wide spectrum of knowledge resources, qualifications and competence profiles of the labour supply create rich opportunities for knowledge exchange and creative interaction between firms and individuals which ultimately result in increased innovation and growth potential, or with the words of Moretti (2012, p 15) "being around smart people makes us smarter and more innovative". There is also a growing number of studies that show not only the importance of proximity to external knowledge but also the need to carry out in-house capacity to acquire useful knowledge inputs from the nearby milieu.

\footnotetext{
${ }^{3}$ In the whole society, the society returns to private R\&D investment are 30 percent greater than the direct business returns. The society returns increases with the density in a given regional setting, and it decreases with the distance between knowledge source and destination (Bloom et al 2013).

4 The patent intensity is about 20 percent higher in a metropolitan area with twice the employment density of another metro area (Carlino et al 2007). Regression analysis on Swedish data shows that the productivity premium associated with persistent $R \& D$ engagement is about 14 percent in the largest city for an individual firm, compared to 8 percent in non-metro locations when the reference firm is a nonR\&D firm in non-metro. A firm without any $R \& D$ engagement does not benefit at all from the external milieu in metro areas (Lööf and Johansson 2014).
} 
Despite significant improvements regarding insights in the mutual link between regional economic milieu and firm capabilities, Carlino and Kerr (2014) suggest that we are only starting to make some progress in understanding how spatial concentration, knowledge spillovers and renewal processes fit together. There are still many remaining challenges to be addressed in empirical research. In particular, it has been shown that the causation can be complex and difficult to disentangle. Another challenge relates to the different proxies used for phenomena that are difficult to observe and measure. There are for instance no uniform or widely accepted definitions for key variables such as knowledge spillover, entrepreneurship and innovation. Instead a broad set of proxies are used which can lead to difficulties in comparing results and establishing reasonably robust relationships.

In contrast to the severe difficulties in finding common definitions of hard-to-measure economic processes, there are well established theoretical concepts of spatially concentrated economic areas where these processes takes place. Originated from Ohlin (1933), the theoretical literature divide this concentration or agglomeration into localization and urbanization economies. Localization economies refer to diversity in a specialized field such that several firms in the same industry collocate in the same region. Urbanization economics refers to variety and colocation of several firms in different industries. The literature mainly considers localization economies as the agglomeration phenomenon that can develop in small- and medium-sized urban regions, whereas urbanization economies is a characteristic of large urban or metropolitan regions.

This special issue "The Geography of Innovation and Entrepreneurship" in Annals of Regional Science collects nine papers which address some of the issues that are included into what Carlino and Kerr (2013) consider as research on agglomeration and spillovers that remains to be accomplished. The papers are using detailed cross-sectional and panel data on observations like innovation, innovation networks, new firm formations, firm characteristics and regional characteristics.

The papers are organised according to their level of analysis, where the first six studies focus on the aggregate regional level and how innovation and renewal is influenced by 
several factors such as industrial composition, labour market characteristics, inmigration and R\&D activities. The remaining three studies uses more disaggregated data and investigate how innovation at the firm level is influenced by network-, R\&D- and collaboration efforts.

The paper Variety, Economic Growth and Knowledge-Intensity of European Regions: A Spatial Panel Analysis, by Nicola Cortinovis and Frank van Oort investigates whether differences in growth between European city-regions can be explained by related and unrelated variety and sectoral specialisation. Employment in detailed 4-digit industries is considered to be functionally related to their 2-digit aggregates, while 2-digit sectors themselves are mutually unrelated. Related variety allows for firms and organizations to access knowledge from complementary sectors and to recombine it into new products or processes whereas ideas and skills are unlikely to spill over when the local milieu is characterized by unrelated variety. By focussing on the sectoral composition of the European city regions the paper is able to provide additional information on the type and functioning of agglomeration externalities. The authors find that related variety externalities do have a positive effect on the economic performance of a region. However, the positive effect is restricted to areas that are more technologically advanced and are better endowed with knowledge and innovation.

The paper Entrepreneurship and Economic Development in Cities by David Audretch, Maxim Belitski and Saameksha Desai examines the direct and indirect effects of new firm formations (entrepreneurship) in 127 European cities over the period 1994-2009. Direct effects are defined as economic growth while indirect effect is more innovation, greater variety and improved competitiveness. The paper finds that entrepreneurship has an immediate, strong and positive effect on urban growth. However, this effect disappears over time in large cities. In small/medium-size a ten percent increase in entrepreneurship correspond to about four percent higher GDP per capita. In contrast to the direct economic impact of entrepreneurship, the indirect effect of new entrants is found to occur only in large cities. The suggested interpretation is that a critical mass is needed to benefit from spillover of knowledge.

The paper by Timo Mitze and Torben Dall Smidt (Internal migration, regional markets 
and the role of agglomeration economies) studies the link between a region's net inmigration rate and proxies for agglomeration economies such as the region's population density, patent intensity, endowment with human capital as well as the region's employment share of knowledge-intensive services. Using data for 95 Danish municipalities over the period 2006 to 2012 to estimate an instrumental variable model allowing space-time dynamic dependence, the paper finds that agglomeration economics are a key driver of internal migration processes.

The paper Causal dynamic effects in regional systems of technological activities - A SVAR approach, by Thomas Brenner and Mattias Dusch applies a data-driven approach to investigate how regional dynamics of economic, research, innovation and educational activities affect each other both instantaneously and over time. The paper analyses five industries in 270 German labour market regions and the data on regional economic activities span over the years 1998 to 2008. It shows different patterns of causality across the five industries. For two industries (chemistry and metal) increased employment stimulates $R \& D$ which then translate into innovations. Among other industries (machinery and transports) past innovations generate opportunities to expand economic activities and employment. The electronic industry is found to stand in-between the two different pattern of causal relationships in the dynamics of regional technological activities.

The paper "What's behind the disparities in firm innovation rates across regions? Evidence on composition and context effects", by Amber Naz, Annekatrin Niebuhr and Cornelius Peters focuses on the association between regional R\&D activity and firm innovative output. To do so, they combine firm level data with information on the regional context of the firms to investigate the determinants of firms' innovation rates. Using a panel data set on more than 6,000 German establishments in manufacturing and services with detailed information on functional regions for the period 1998 to 2009, the authors find that the mean innovation rates differ significantly across distinct types of regions. The regression results show a positive association between regional R\&D activity and firm's innovation performance. However, the internal firm level determinants appear to be more important than the external regional environment. 
In the paper "Market potential and the location of knowledge intensive services comparing different geographical solutions", Therese Norman and Johan Klaesson compare the relationship between innovation and proximity to markets in two different geographical levels. The first level is the Swedish economy separated into all its 290 municipalities. The second level is a single Swedish county (Jönköping) separated into 298 small local areas. In the study, regional innovativeness is proxied by employment in knowledge intensive industries. The market potential is proxied by number of jobs in the nearby geographical area. The empirical analysis suggests that the very detailed level analysis (Jönköping) is appropriate for studying the link between highly knowledge intensive industries and the local economy, while the more aggregate level may be more suitable for other industries.

The paper On the trail of core-periphery patterns in innovation networks - measurement and new empirical findings from the German laser industry, by Muhammed Kudic, Wilfried Ehrenfeld and Toralf Pusch, examines bi- and multilateral R\&D cooperation activities for the full population of German laser sources over the period 1990 to 2010. There is a wide knowledge gap regarding how a company can exploit cooperation in the innovation network to access information, and absorb technological knowledge. The paper suggest that geographical location does not play any significant role for an organization's ability to gain fast access to the technological knowledge embodied in the core of the industry's innovative network.

Lina Bjerke and Sara Johansson also consider how firms can benefit from collaboration ("Innovation and firm collaboration - An exploration of survey data"). Their study is based on a Swedish regional Community Innovation Survey (CIS) type of questionnaire which provides information how collaboration correlates with innovation for both micro-firms (1-9 employees) and other firms. The analysis distinguishes between intra-regional and extra-regional and international collaboration, and it also consider possible difference between vertical and horizontal linkages. The result suggests that only collaboration with suppliers and customers are positively associated with innovation. However, the extra-regional collaboration partners are more important than customers and suppliers in the nearby milieu. In particular small firms seems to benefit more from extra-regional collaboration compare to nearby partners. A possible explanation is that too much 
proximity may result in lock-in effects for these firms.

In the paper "Knowledge Spillovers, Productivity and Patent", Hans Lööf and Pardis Nabavi examine potential heterogeneity in the capacity to benefit from knowledge spillover among multinational firms (MNE). Firms belonging to a MNE group have the internal network of the group as an infrastructure for knowledge interaction. The global location of subsidiaries makes it possible for individual firms in a group to tap knowledge from different knowledge centers around the world. What is then the importance of the regional milieu? The paper considers four binary categorizations: domestic and foreign MNE; location within or outside a metropolitan area; high-tech and non high-tech firms; using innovation (patent) and productivity as outcome variables. Analysing around 900 multinational firms over a 16 year period, the paper reports varying results to depending on the firm category [of firm] and output measure. A key finding is that foreign foreign firms tend to benefit more from being located in a metro areas than their domestic counterparts in terms of productivity. The result is the reverse when regards to innovation. However, the first finding is only significant for non hightech firms, whereas the other is statistically significant only for high-tech firms.

We end this introductory text by summarizing some of the main contributions from the included papers. More recently innovation and entrepreneurship have come to obtain a central position in this literature. A main reason for this is the emergence of the knowledge-driven economy and its prominent role for positive externalities and spillovers. Krugman (1991) suggests that spillovers cannot easily be measured and tracked because knowledge flows are invisible to a large extent. More recent research, however has made important progress in the attempt to open the black box. This special issue adds to the understanding of the geography of innovation and entrepreneurship by suggesting alternative ways of identifying spillovers, combing and integrating internal and external knowledge sources, and by estimating the impact on innovation, new firm formation and growth.

The nine papers included examine innovation and entrepreneurship at both the aggregate regional level and between firms in different regional settings. All papers make use of extensive and detailed data sources that enables to give a richer picture of 
how innovation, entrepreneurship and growth are influenced by factors like spatial concentration, industry composition, labour market characteristics, immigration, firm characteristics, R\&D activities and R\&D collaboration. A general reflection is that the more detailed data at the level of individuals, firms, industries and regions, reinforces the picture of the geography of innovation and entrepreneurship as heterogeneous and complex. 


\section{References}

Bloom N, Schankerman M, Van Reenen J (2013) Identifying Technology Spillovers and Product Market Rivalry. Econometrica 81 (4): 1347-1393

Carlino G, Carr J, Hunt R, Smith T (2012) The agglomeration of R\&D labs. Federal Reserve Bank of Philadelphia Working Paper: 12-22

Carlino G, Kerr WR (2014) Agglomeration and Innovation. National Bureu of Economic Research Worling Paper 20367

Krugman P (1991) Increasing returns and Economic Geography. Journal of Policitical Economy 99(3): 483-499

Loof H, Johansson B (2014) R\&D Strategy, Metropolitan Externalities and Productivity: Evidence from Sweden. Industry and Innovation 21 (2): 141-154

Marshall A (1890) Principles of Economics. London: Macmillan and Co., Ltd.

Moretti E (2004) Workers' Education, Spillovers, and productivity: Evidence fom PlantLevel Production Functions. American Economic Review 94 (3): 656-690

Ohlin B. (1933) Interregional and international trade. Cambridge, MA: Harvard University Press 